- The profession has a responsibility to ensure that people from all societal groups have access to oral health care services with good and equitable outcomes.

- The majority of people with a disability can, and should, be treated in mainstream general dental services.

- This paper explores models of good practice, the skills mix and facilities required to provide Special Care Dentistry and makes recommendations for future training and service delivery.

\title{
Special Care Dentistry: a professional challenge
}

\author{
J. E. Gallagher ${ }^{1}$ and J. Fiske ${ }^{2}$
}

As a profession we have a responsibility to ensure that the oral health needs of individuals and groups who have a physical, sensory, intellectual, medical, emotional or social impairment or disability are met. In the UK, over 200,000 adults have profound learning disabilities and/or complex medical conditions. Adults with a disability often have poorer oral health, poorer health outcomes and poorer access to services than the rest of the population. This paper examines the need for Special Care Dentistry based on a review of published literature, surveys and health policy, and suggests how services might be delivered in the future.

Existing models of good practice reveal that established clinicians working in this field have a patient base of between 850 and 1,500 patients per year and work across primary care and hospital settings, liaising with colleagues in health, social services and the voluntary sector to ensure integrated health care planning. On this basis, a conservative estimate of 133 specialists is suggested for the future, working in networks with Dentists with Special Interests (DwSIs) and primary dental care practitioners. A skilled workforce that can address the wider needs of people requiring Special Care Dentistry should be formally recognised and developed within the UK to ensure that the needs of the most vulnerable sections of the community are addressed in future.

\section{INTRODUCTION}

Special Care Dentistry (SCD) is concerned with providing and enabling the delivery of oral care for people with an impairment or disability, where this terminology is defined in the broadest of terms. ${ }^{1}$ Thus, SCD is concerned with:

'The improvement of oral health of individuals and groups in society who have a physical, sensory, intellectual, mental, medical, emotional or social impairment or disability or, more often, a combination of a number of these factors'.

\footnotetext{
1*Senior Lecturer/Honorary Consultant in Dental Public Health, King's College London Dental Institute, Caldecot Road, London SE5 9RW; ${ }^{2}$ Senior Lecturer/Honorary Consultant in Special Care Dentistry, King's College London Dental Institute, Guy's Hospital, London Bridge, London SE1 9RT

${ }^{*}$ Correspondence to: Dr Jenny Gallagher Email: jenny.gallagher@kcl.ac.uk
}

\section{Refereed Paper}

Accepted 4 August 2006

DOI: 10.1038/bdj.2007.426

${ }^{\circledR}$ British Dental Journal 2007; 202: 619-629
It is defined by a diverse client-group with a range of disabilities and complex additional needs and includes people living at home, in long stay residential care and secure units, as well as homeless people.

At a time of immense change for our profession and the health services it delivers, this paper examines the need for SCD and suggests how services might be delivered in the future. Providing access to NHS dentistry has become an important social and political issue, with commitments from the Department of Health to reform NHS dentistry and to bring it more firmly into the NHS. ${ }^{2,3}$ The Health and Social Care Act $^{4}$ set the legislation for local commissioning of NHS dentistry by Primary Care Trusts (PCTs) in England and Local Health Boroughs (LHBs) in Wales. Following this legislation, there has been phased entry into local commissioning via Personal Dental Services (PDS), with all of primary dental care entering new arrangements from 1 April 2006. ${ }^{5}$ The policy focus on dentistry has resulted in increased funding for primary dental care to facilitate workforce expansion, in the short and medium term, to meet the needs and demands of the population in a devolved manner. ${ }^{3,6}$

Specialist services have not been immune from change. In recent years the training and accreditation of specialists has been formalised and closely regulated through the Royal Colleges, and the creation of specialist lists held by the General Dental Council (GDC) has resulted in a greater number and range of specialists. Many dentists achieved entry to specialist lists by mediation on the basis of their experience. The implications of these changes have been re-examined by the Standing Dental Advisory Committee ${ }^{7}$ and more recently the GDC which has approved the development of a speciality in Special Care Dentistry. ${ }^{8,9}$ At the same time, following the lead of our medical counterparts, 
a new tier of DwSIs is heralded within the NHS. ${ }^{10,11}$ These practitioners, holding defined competencies somewhere between those of a generalist and specialist, will add to the complexity of the current system where specialists already hold overlapping competencies. ${ }^{12}$ However, if established in a co-ordinated manner, DwSIs may provide improved access to care, optimal use of skills and seamless care for patients.

Community and salaried dental care services, which include both generalists and specialists, have also been reviewed. ${ }^{13,14}$ The future delivery of these services has major implications for the provision of SCD which has increasingly become one of the salaried dental service's functions over the past two decades, in line with health service guidance. ${ }^{15,16}$ Furthermore, the British Society for Disability and Oral Health (BSDH) has been commissioned to develop guidance for PCTs on commissioning DwSIs in SCD through a clearly defined competency framework. Additionally, the immediate past Chief Dental Officer for England (Professor Raman Bedi) commissioned a strategic review of the oral health needs of older people and how they can be met. This review lays out clear guidance for planning and commissioning of local services, some of which will be for SCD. ${ }^{17}$

Against this complex background, the current paper examines the arguments for and against the provision of SCD for people with disability and/or complex additional needs. The size of the population who may require SCD is discussed, along with their oral health needs. Models of care, both generalist and specialist, are explored to provide an indication of workforce needs. Finally, the steps that would make this vision a reality are outlined.

\section{THE SIZE OF THE CHALLENGE}

The Joint Advisory Committee for Special Care Dentistry ${ }^{9}$ has identified the population who require the services of special care dentistry as: 'Individuals and groups in society who have a physical, sensory, intellectual, mental, medical, emotional or social impairment or disability or more often a combination of a number of these factors.'

There is no ready made database to provide figures for the proportion of the population that fall within this definition. National Census data and literature on disability and impairment from a range of sources were accessed to determine the volume of people likely to require SCD (Table 1). Throughout the rest of this paper the term 'disability' will be used to cover the range of people who fall within this definition.

Based on the reported problems of people with a disability and their carers, it is estimated that as many as one in four adults within the UK has experienced, or will experience, a disability during their lifetime. ${ }^{18}$ The number of people reporting a long term illness, health problem or disability increased significantly between the 1991 and 2001 Censuses. ${ }^{19}$ In England and Wales, recent data indicate that almost 9.5 million people (18.2\% of the population) self-report a long-term illness, health problem, or disability which limits their daily activities or work. ${ }^{18}$ Whilst self-reported morbidity must be viewed with some caution, ${ }^{20}$ the impact on society cannot be ignored as more than one in eight of these people (4.3 million) are of working age (16-64 for men and 16-59 for women). ${ }^{18}$ Similar levels of disability are reported in Scotland and Northern Ireland..$^{21,22}$

There is no single register for disability, and a proportion of people with disability have multiple impairments and/or medical conditions so that the categories of disability and impairment, such as those outlined in Table 1, may overlap. For example, people with cognitive impairment have an increased prevalence of associated disabilities such as physical or sensory impairments, behavioural differences and epilepsy. ${ }^{23,24}$ Furthermore, with ageing, people with learning disabilities also have a higher rate of dementia than the general population. ${ }^{25}$ Disability tends to increase with age and multiple disabilities are more likely to occur in old age. ${ }^{26,27}$ Indeed, approximately two thirds of all people with a disability are aged 65 years or over. In contrast, only $9 \%$ of teenagers aged 16-17 has a current long-term disability and one third of people aged between 50 and 65 years report a disability. ${ }^{18}$ There is also a substantial group of adults, including those under the age of 65 years, with complex long-term medical conditions. Although older people form an increasing proportion of people with a disability, it must be remembered that only a relatively small proportion of older people (5\%) live in care homes.
However, this proportion increases with age such that $20 \%$ of people aged 85 years and over and almost half (48\%) of people aged 95 years and older live in care homes. ${ }^{28}$

These data highlight that there is a spectrum of disability (from mild, through moderate to severe) which has implications for access to mainstream dental services, ${ }^{29}$ as shown in Figure 1. The majority of people with a disability have disabilities that are minor or moderate and, in the context of normalisation, should, and possibly do, have little difficulty in accessing and using mainstream primary dental care. The greater challenge to the profession is the section of the population with more severe or complex disability and medical conditions, who are less able to access, use and co-operate with mainstream primary dental care, and who require specialist skills and management in order to have their oral health needs met. Within England, an estimated 210,000 people have a profound learning disability, a third of which are children and young people, whilst a further 1.2 million people have a mild or moderate disability. ${ }^{30}$ Overall there is likely to be an adult population of at least 200,000 people with extreme disability and/or complex needs in the UK. Other groups within society that may require special care dentistry on a short-term basis include people in secure units and homeless people. There is no single universally agreed definition of homelessness and this substantial, mobile community is hidden or hard to reach in society. ${ }^{31}$

\section{THE CHANGING NEED FOR SCD}

A range of factors may increase or reduce the need for SCD and should be monitored so that dental and other health services can be planned to meet need. The most important of these factors would seem to be the ageing population, changing public values and expectations, and reforms of health services, together with changing patterns of oral health.

\section{a) Demographic change}

As more people survive into old age, there will be an increasing volume of older people who are likely to develop disability coincidental or consequential with ageing. More people with learning disabilities will survive into their 50 s and 60s, facing the challenges of 
Table 1 Volume of people with an impairment or disability within the UK

\begin{tabular}{|c|c|c|}
\hline Category & Volume of need & Source \\
\hline $\begin{array}{l}\text { Physical impairment or } \\
\text { disability }\end{array}$ & $\begin{array}{l}8 \text { million people are affected by diseases } \\
\text { relating to arthritis } \\
73 \% \text { of people with arthritis have difficulty } \\
\text { in carrying out usual daily activities }\end{array}$ & $\begin{array}{l}\text { DCMS Towards } 2004 \text { seminar, } \\
18 / 07 / 00\end{array}$ \\
\hline $\begin{array}{l}\text { Sensory impairment or } \\
\text { disability }\end{array}$ & $\begin{array}{l}5.8 \text { million people have hearing loss } \\
1.7 \text { million people have a serious sight } \\
\text { problem }\end{array}$ & $\begin{array}{l}\text { DCMS Towards } 2004 \text { seminar, } \\
18 / 07 / 00\end{array}$ \\
\hline $\begin{array}{l}\text { Intellectual impairment } \\
\text { or disability }\end{array}$ & $\begin{array}{l}1.2 \text { million people are registered with a } \\
\text { learning disability in England } \\
210,000 \text { (children and adults) have a } \\
\text { severe/profound disability } \\
1-2 \% \text { of the population have a mild or } \\
\text { moderate learning disability ( } 1.2 \text { million in } \\
\text { England) } \\
10,000 \text { with a disability live in NHS facili- } \\
\text { ties and } 53,000 \text { in residential care }\end{array}$ & $\begin{array}{l}\text { Department of Health }{ }^{26} \\
\text { Disability partnership }{ }^{21}\end{array}$ \\
\hline $\begin{array}{l}\text { Mental impairment or } \\
\text { disability }\end{array}$ & 7.2 million cases of mental health problems & $\begin{array}{l}\text { DCMS Towards } 2004 \text { seminar, } \\
18 / 07 / 00\end{array}$ \\
\hline $\begin{array}{l}\text { Social impairment or } \\
\text { disability }\end{array}$ & 250,000 have a severe facial disfigurement & $\begin{array}{l}\text { DCMS Towards } 2004 \text { seminar, } \\
18 / 07 / 00\end{array}$ \\
\hline $\begin{array}{l}\text { Developmental impair- } \\
\text { ment or disability }\end{array}$ & $\begin{array}{l}\text { Down syndrome: } 1.5 \text { per } 1,000 \text { births } \\
\text { Edward syndrome: } 0.3 \text { per } 1,000 \text { births } \\
\text { with only } 10 \% \text { of children surviving the } \\
\text { first year } \\
\text { Cerebral palsy develops in } 2-3 \text { per } 1,000 \\
\text { live births }\end{array}$ & Disability partnership ${ }^{14}$ \\
\hline Older people & 9.4 million ( $16 \%$ of UK population) & Tinker ${ }^{22,23}$ \\
\hline Total disability & $\begin{array}{l}9.4 \text { million adults } \\
0.4 \text { million children }\end{array}$ & $\mathrm{ONS}^{14}$ \\
\hline & & \\
\hline
\end{tabular}

older life at a premature age. ${ }^{30}$ Furthermore, improved paediatric care means that increasing numbers of children born with complex and multiple disabilities are surviving into adulthood, eg children with complex congenital heart conditions, and they will require special dental management throughout their lives. As a result, these children, who have received specialist paediatric dental care, are likely to have raised expectations of continuing to receive care within a specialist service as they move into adulthood. All these factors will result in an increasing need and demand for SCD.

\section{b) Increasing population expectations}

Public expectations are changing. People want to retain their natural teeth in order to look good, feel good about themselves and to be socially acceptable; they want their mouths to be comfortable; and they want to be able to enjoy their food. ${ }^{32,33}$ This expectation is the same for people with and without disability. ${ }^{34}$ The emotional effects of tooth loss are now well recognised and require sensitive handling in all age groups, particularly in older people as total tooth loss becomes less common and thus less socially acceptable. ${ }^{35-37}$ To achieve this end, people increasingly wish to retain their natural teeth and will make greater demands on the dental profession, including specialist care. $^{32}$

\section{c) Survival from cancer}

Increased numbers of people can be expected to undergo and survive treatment for head and neck cancer and other serious medical conditions. Their dental management may require specialist input both pre- and post-operatively.

\section{d) Lack of other specialists to carry} the workload

Children with specialist oral care needs are catered for by paediatric dentists. If their access to oral care is to be assured as they move through adolescence to adulthood, this will require transition to other oral health specialists skilled in their management. Historically, many adults with disabilities received routine care from paediatric dentists and surgical care from oral and maxillofacial surgeons (OMFS). These former arrangements are no longer considered appropriate and, even if they were, there are insufficient dentists in these specialty areas to provide the level of care required. Treatment under general anaesthesia through the OMFS service has reduced as the specialty has expanded its base from dento-alveolar and facial surgery to head and neck surgery. Also, dental treatment under general anaesthesia has become less appropriate as the treatment needs of people with disability are now considered to routinely include preventive and restorative dentistry rather than being predominantly exodontia. In some instances this care has been picked up by the Community Dental Service, with comprehensive oral health care provided by staff working across settings, but often under the auspices of other hospital consultants in order to gain access to specialist facilities, such as general anaesthesia lists and beds. ${ }^{1}$

Advanced restorative dental services are in high demand and short supply nationally. Although consultants and specialists in restorative dentistry may have developed skills in the field of SCD, capacity issues alone will minimise their contribution to the oral health care of people with disability and there is currently wide support amongst specialists for a new specialty of SCD. ${ }^{38}$

\section{e) Policy}

Current policy (for example, National Service Frameworks and Clinical Outcomes Guidelines) recommends that certain patient groups and/or types of care should be restricted to designated specialists in dedicated centres and that the more vulnerable groups of the population with a special health need receive the full range of health care (including routine dentistry) in that centre. ${ }^{30,33}$ This ethos has focussed clinical governance and quality standards on the 


\section{Spectrum of Need \&t Disability}

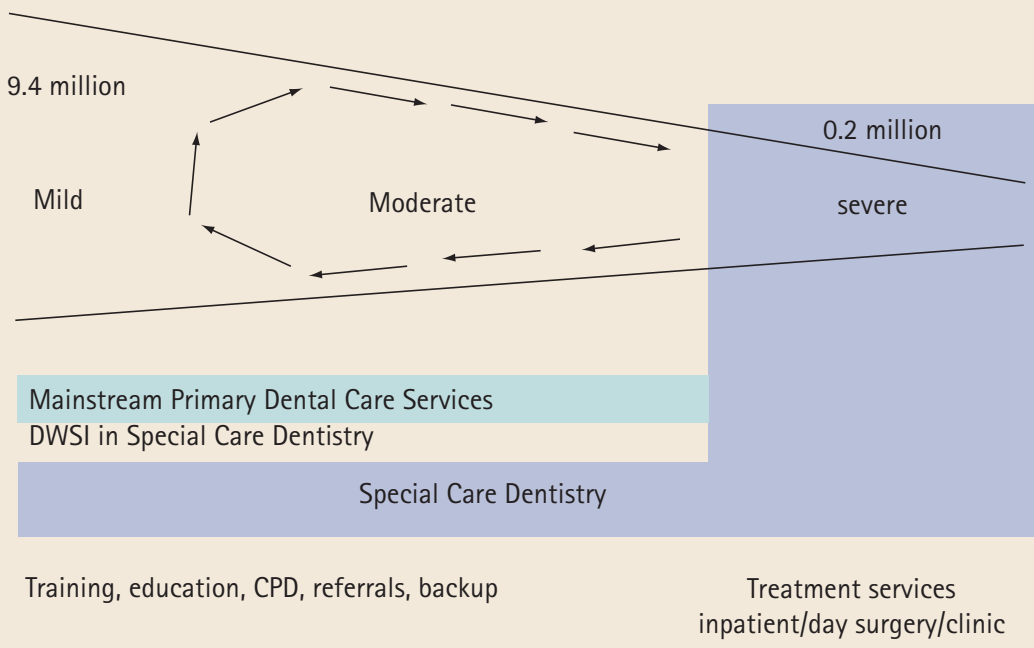

Fig. 1 The integrated role of Special Care Dentists (Source: JACSCD')

centralisation of care by trained experts who have clearly identified roles. This will contribute to an increase in the need and demand for specialists.

\section{f) Changes in primary care dentistry}

It is appropriate for most people with mild or moderate disability to receive care from a primary care practitioner. It remains to be seen how new methods of regulation and financing primary dental care under the Health and Social Care Act impact on the attractiveness, to practitioners, of providing care for people with disability within general dental practice. ${ }^{4,39}$ If changes result in people with an impairment or disability being more able to access routine care and to benefit from a preventive approach, this may lead to a welcome reduction in their need for treatment. ${ }^{2,6}$ Paradoxically, the same changes may make it more difficult for people requiring specialist services, such as domiciliary care, to access it through primary dental care as it is being commissioned as a 'specialised service' and will no longer be part of mandatory services. ${ }^{39}$

\section{g) Improving oral health}

Recent decades have seen improved oral health in children and young adults. This will translate across the population, thus reducing the complexity and volume of oral health needs of children and younger people. However, adults aged
40 years and over generally have heavily restored dentitions. ${ }^{32}$ They will still require significant amounts of care and maintenance, and the majority of people requiring SCD of an invasive nature (such as fillings, crowns and bridges, and implants) fall into this category.

\section{On balance}

On balance, the section of the population with disabilities and/or complex additional needs is likely to require specific care in the medium term and the main challenge is providing access to appropriate services. This includes the need to tailor the workforce to the population changes. As with all specialties this will require ongoing monitoring.

\section{ORAL HEALTH NEEDS AND DEMANDS}

There is an ongoing debate as to what constitutes 'need' and how need should best be assessed in public health services. ${ }^{40-44}$ 'Need' has been defined as 'the population's ability to benefit from health care, ${ }^{,} 4,41,45$ thus, making the link between health needs and health care. It is important to realise that need is not static but open to interpretation; it changes over time; and is influenced by a range of forces including supply and demand..$^{41,45}$ Oral health needs are no different to general health needs in this matter. However, the management of the oral health needs of people with disability cannot be undertaken without reference to their disability and the health and social teams providing their care. This is particularly the case for people with more extreme disabilities to ensure that inequalities are minimised. ${ }^{46}$

\section{THE VOLUME OF ORAL DISEASE}

Although improvements in oral health have occurred across all sections of the community, ${ }^{32}$ socially disadvantaged people continue to have the poorest levels of oral health. As people retain their teeth, this presents challenges to the dental profession in providing care to people who are medically compromised, multiply disabled and older who may require a wide range of interventions in a heavily restored dentition, often at a time in their lives when they are less able to cope with treatment.

\section{Unmet current need}

Ideally, people with and without disability should have equitable oral health outcomes in terms of self-esteem, appearance, social interaction, function and comfort. ${ }^{1}$ However, despite overall improvements in the country's oral health, inequalities still exist. Lower levels of oral health have been demonstrated in a range of patient groups, including people with learning disabilities, ${ }^{23}$ cerebral palsy, ${ }^{47}$ epilepsy, ${ }^{48}$ multiple sclerosis ${ }^{49}$ and psychiatric illness. ${ }^{50}$ This situation has also been identified amongst young disabled people ${ }^{51}$ and older people, ${ }^{52}$ particularly those in care homes. There is evidence that people with learning disabilities or mental health problems have the same oral diseases as the general population but are likely to have poorer oral health and poorer oral health outcomes. ${ }^{53,54}$ Also, people with disability who are living in community settings are less likely to have received dental treatment than those people in the general population. ${ }^{53}$ Furthermore, when treatment does occur, people with disability are more likely to receive extractions than fillings, crowns and bridges. ${ }^{53,55,56}$ Again, this is particularly the case for older people living in care homes.

There is evidence that people with mental health problems, such as schizophrenia, often have advanced dental disease. ${ }^{57}$ Reasons for this include: psychotic condition impairing the ability to plan and perform oral hygiene procedures; some antipsychotic medications 
causing xerostomia that predisposes to dental caries; and difficulty gaining access to general dental practice, where they are not always welcomed..$^{57}$

Whilst the oral health needs of young people with disability are rooted in the specialty of paediatric dentistry, a key issue for this group is the smooth transition during adolescence from specialist children's services to specialist adult services. ${ }^{58,59}$ Transition usually occurs at 16 years but there is some evidence that this is moving towards 14 years ${ }^{60}$ and, in some cases, is as early as 12 years. ${ }^{61}$

In her introduction to the BSDH Winter Scientific Meeting 2004, Brookes highlighted that the BSDH Secretary alone received over 1,000 calls and letters per year from people with a disability and/or carers desperately trying to access dental care services. ${ }^{62}$ This highlights both the difficulty in accessing oral health care and the need for improved information for the public on available services.

\section{CURRENT SERVICE PROVISION}

Currently there is neither a recognised specialist training pathway nor a clear career progression for dentists wishing to specialise in the area of SCD. Additionally, the ad hoc service arrangements for people with a disability are reported as being insufficient to meet needs and demand and highlight the fact that providing dental care to people with a disability is often a low priority. ${ }^{34}$

\section{a) Current workforce}

Most dentists working in the field of SCD are based in the salaried Community Dental Service. ${ }^{38}$ There is a smaller constituent of SCD based in general and teaching hospitals who are either salaried NHS or university staff. General dental practitioners contribute to the overall picture of $\mathrm{SCD},{ }^{63}$ but only a small number of practitioners have a specialist interest in this field, and only four of the 120 people $(0.33 \%)$ attending the British Society of Gerodontology meeting in December 2004 were general dental practitioners.

\section{b) Current training}

On the whole, individuals who have undertaken training in SCD have been responsible for their own training, formal and informal, perhaps with the support of a proactive manager, and often on an ad hoc basis. This must be formalised in the current changes to primary care dentistry within the NHS and professionally through the GDC review of specialties. It should not be left to the individual dentist to fund their training in SCD, as with some of the dental mono-specialties. Within SCD, there will be fewer opportunities for a private or mixed economy and the funding for SCD is likely to fall firmly within the remit of the NHS. Additionally, the adverse influence of student loans on new graduates' abilities to pay for postgraduate training must be recognised, and addressed, in order to safeguard future specialist training.

\section{c) Current delivery of SCD}

As SCD is not yet an established specialty, the hospital-based services which do exist (often provided by the Community Dental Service) depend upon the goodwill of specialist and consultant colleagues (under whose auspices the service is provided) to gain access to facilities such as general anaesthesia operating lists. This increases the complexity of the services and the difficulty of coordinating the various agencies involved in an individual's care.

Specialists' work need not, and indeed should not, be restricted to working in hospitals. ${ }^{64}$ Local studies demonstrate that general and community dental services provide the majority of the currently supplied care for people living in community settings who are on disability registers. ${ }^{64}$

A study on the views and experiences of parents of adults with Down Syndrome regarding oral health identified that people want to be treated with the same standards as people without disability. ${ }^{65}$ They wanted good access to mainstream dental services with the support of expert or 'specialist' advice, care and facilities as required. Far from feeling that this was the case, examples of professional diffidence and less than optimal care were cited. A survey of adults with learning disabilities living in the community, and known to social services in South East London, revealed that people with learning disabilities and their carers would like more services for people with learning disabilities including the use of mobile clinics. ${ }^{63}$ There are increasing concerns that mainstreaming people with a disability may result in neglect and that there may be benefits in some dedicated services, with access to specialist care when required.

\section{d) Current caseloads}

Typical specialist caseloads in Special Care Dentistry are difficult to estimate. In an effort to illustrate 'specialist' caseloads, four examples are drawn from experienced clinicians working in this field of dentistry in different areas of the UK. ${ }^{1}$ Their activities (outlined in Fig. 2) involve a caseload of between 850 and 1,500 patients per year. Most of these patients are likely to be higher risk than average and are likely to require health reviews more frequently than once every two years. These caseloads may inform a 'best fit' calculation for the number of specialists required in SCD. They assume annual dental visits for the patients that make up this complex caseload, albeit that some patients will require a less frequent, and others a more frequent, assessment based on NICE Guidelines. ${ }^{66} \mathrm{~A}$ specialist service contract should specify the timing of regular assessments plus care packages based on individual need.

\section{e) Service uptake}

There are no national data on the use of NHS primary dental care services by people with physical or learning disabilities. However, registration rates for older people with general dental services in England are below the average for the general population, ${ }^{17,67}$ and are likely to be lowest for disabled older people who form a significant proportion of this group. Proactive promotion of appropriate services will be required to improve current levels of uptake. ${ }^{38}$ Barriers to accessing dental care cover a range of problems. The policy document Valuing people recommends mainstreaming care rather than providing specialist services. ${ }^{30,68}$ However, physical mobility has a significant association with all aspects of attending the dentist and maintaining oral health. ${ }^{69}$ For example, dental premises may not be accessible to all people with a disability. In London, people with a disability are four times more likely than non-disabled people to find dental practices unsuitable or inaccessible. ${ }^{70}$ Thus, there is greater need for accessible and acceptable dental services to be made available in a proactive manner to defined vulnerable groups within society. 
BSDH guidelines recommend continuity of care where possible for people entering long-stay institutions. ${ }^{71}$ The problem of receiving care from a GDP may be exacerbated under new local commissioning arrangements as there is no longer a specific fee nor the flexibility for any dentist to undertake domiciliary visits. Instead these will be specified within contract for a limited number of practitioners. The pilot PDS scheme allowed innovative services for older people in care homes to be developed. ${ }^{17}$ It is unlikely that the new system will encourage or easily facilitate practitioners to expand into domiciliary care. Primary Care Trusts will have to ensure that there are clearly signposted pathways to care for people with disability, in particular for those requiring domiciliary services, to ensure that there is access to care commensurate with local need. ${ }^{17}$ In monitoring the newly introduced payment system, it will be important for local NHS organisations and the National Implementation Review Group to consider its impact on dentists who provide care, and on the care received by people with disability who often require longer periods of time than other sectors of the population for the delivery of similar amounts of treatment. This will be important to uphold the Disability Discrimination Act, and to avoid unnecessary challenge by the Discrimination Rights Committee.

\section{FUTURE MODELS OF CARE}

\section{Ethos of care}

Special Care Dentistry has a broad based philosophy which takes a holistic view of oral health and requires specialists to liaise and work with all those members of an individual's care team. This is particularly important in the case of people at the more severe end of the spectrum of disability, where a greater range of issues needs to be considered.

\section{Evolving recognition of the need for the} Specialist in Special Care Dentistry Generally, people requiring SCD have needs that are wider than oral health. For example, providing oral care for persons with cognitive impairment may involve working with advocates; organising, attending and informing 'best interest meetings' where decisions are made about care; taking responsibility for obtaining informed consent; and using tools such as Makaton and Easy Read for communication. Dentists who are currently practising SCD are cognisant with the signs and symptoms of specific medical conditions and are likely to feel confident in treating people with such conditions, obtaining consultative advice from medical specialists, and contributing to 'best interest meetings'. ${ }^{72}$

Kiyak emphasises the need for positive attitudes towards disability amongst dentists and calls for specialist training to improve access to care. ${ }^{73}$ Together with increasing international recognition of the need for such a specialty, ${ }^{1}$ support for SCD to become a recognised specialty has been forthcoming from the BDA,,$^{52}$ the Standing Dental Advisory Committee, ${ }^{9}$ the Strategic Review Group for Oral Health Care for Older People, ${ }^{17}$ and, most recently, the GDC. ${ }^{8}$ In December 2005, the GDC council meeting ratified the proposal for the development of a Specialty in Special Care Dentistry. ${ }^{8,9}$

\section{Calculating the numbers}

Specialists actively working in the field of SCD should be achievable through mediation, and this will be up to the GDC. Assuming the freedom to rationally plan for SCD within the NHS, it is helpful to look first at other specialties which base their service planning on the total local population; then at primary dental care caseloads; and, finally, relate the level of need in the UK to typical caseloads of those who currently provide SCD. In doing so it is clear that none of these planning models is ideal for SCD. However, it is helpful to relate consultant numbers to the total resident population, generalist caseloads and case list sizes for senior clinicians already working in SCD.

If planning were to be based on specialties which are accessed on a referral basis, such as oral maxillofacial surgery, there would be approximately 400 consultants in the UK using the recommended ratio of three consultants to $450,000-500,000$ of the total national population. ${ }^{74}$ As SCD does not serve the whole population, calculations based on the total population are not appropriate and the numbers reached by this method would be unrealistic.

As ongoing routine care will be required for many people with disability, it is useful to compare the situation with that of the Primary Dental Care sector. This suggests a notional GDS ratio of up to $1: 3,000$ population for the provision of Primary Dental Care. However, many general dental practitioners appear to have smaller numbers of registered NHS patients, eg 1,000-2,000, which may relate to their hours of working or their mix of NHS and private care. Thus, taking a dentist to population ratio of somewhere between 1,000 and 2,000 patients would mean that, for a special care population of 200,000 in the UK, between 100 and 200 specialists would be required.

Specialists in SCD would have parallels in both the above systems, as they will provide a secondary referral base for people with mild or moderate special needs, who routinely access primary dental care services, and ongoing care for people with more complex disability and additional needs.

Therefore, a reasonable way of looking at this issue is to use the 'typical existing caseloads' of people who practise SCD (set out in Section 5 of this paper), whereby a caseload of between 850 and 1,500 patients is appropriate for a whole time specialist. ${ }^{1}$ Using this approach, planning for regular care of a UK population of 200,000 people (whose degree of disability precludes their routine care in primary dental services) SCD would require between 133 and 235 specialists for a population base of 200,000 people with disability where ongoing care is provided. This would suggest a minimum of 133 specialists in the UK. For an authority with an average population of 1.5 million, this would translate to four specialists in SCD. This would not seem an unreasonable place to start. However, local service planning should be informed by local needs assessment and review of current service provision.

In 2003, JASCD ${ }^{38}$ calculated that there were:

- Approximately six established academics in the field of SCD

- Less than 40 hospital dentists in SCD

- Approximately 674 Senior Community Dental Services staff, of whom 137 were managers and 537 Senior Dental Officers.

and that:

- The number of general dental practitioners with specialist expertise is unknown and not obtainable, but is 


\section{I: South Wales: Dental Hospital (DH)}

\section{$\rightarrow$ The referral base is extensive serving a population of I,797,000 people}

$\rightarrow$ The Dental Hospital provides a comprehensive service for Special Care patients and serves a large Medical School and Hospital with Specialities such as the Regional Haemophilia Centre, Genetic Centre, Cardiac Services, Renal Unit and Oncology Services

$\rightarrow$ Patients are accepted for Specialist treatment within the Department or directed to CDS or GDS services following referral as appropriate

$\rightarrow$ Some consenting patients will be suitable for the revised undergraduate Special Care Dentistry curriculum and will be channelled into care through the clinical teaching programme

$\rightarrow$ With improvement of Trust and CDS facilities, more patients will be able to receive their treatment in a primary care setting with 'shared care' for particular aspects of their care.

\section{2: Lothian: Community Dental Service (CDS)}

$\rightarrow$ Patient referrals come from the Primary and Secondary Care sectors. Many of them come from Colleges in the Edinburgh Dental Institute who are Consultants and Specialists in Restorative Dentistry, Oral Surgery and Oral Medicine.

$\rightarrow$ There are a number of SDOs with different roles allowing cross referral as appropriate to provide a seamless provision of care between the District General Hospital (DGH) and community setting

$\rightarrow$ The CDS has access to dental surgeries in all three of the DGHs so that patients can be transferred to a hospital clinic for part or all of there treatment depending on its complexity and their medical history

$\rightarrow$ The CDS is a regional centre for the South East of Scotland for the provision of dental care for older people with haemophilia. It is also a regional centre for oncology

$\rightarrow$ The CDS staff work with General Dental Practitioners at several levels:

- Accepting referrals

- Providing advice and treatment plans

- Shared care of patients who are returned for continuing care with the practitioners having open door access to the CDS

- Provision of training courses.

\section{3: North of England: General Hospital with Specialist Facilities}

$\rightarrow$ Referrals are received from General Medical and Dental Practitioners working in the Primary Care Sector

$\rightarrow$ The limited resources mean that patients can not be accepted for continuing care but for single course of, or one-off, treatments

$\rightarrow$ The Special Care Dentistry hospital-based service is required for:

- People with complex medical status

- Provision of shared care within hospital Specialities

- Complex management of people that is beyond the scope of management in the Primary Dental Care setting eg those who cannot be sedated with GA but can be treated with conscious sedation

- Comprehensive care and joint planning with other Dental Specialists (links with Maxillofacial surgeons and Specialists in Restorative Dentistry - including Prosthodontics) eg for patients with craniofacial abnormalities.

4: London: Dental Hospital (DH)

$\rightarrow$ Patient referrals are received from the Primary and Secondary Medical and Dental Care Sectors including from Consultant and Specialist colleagues in Paediatric Dentistry, restorative Dentistry, Oral Surgery and Oral Medicine within the hospital base and from other hospitals throughout the South East of England and other regions

$\rightarrow$ The Department acts as a regional centre for some groups of patients eg those with haemophilia, oncology, epidermolysis bullosa, positive HIV status and dental phobia

$\rightarrow$ The Special Care Dentistry hospital-based is required for:

- Advice and support for General Dental Practitioners

- Treatment for people with complex medical status, progressive medial conditions, severe learning disability, severe mental health problems, dental phobias, etc

- Provision of shared care within hospital Specialities

- Complex Management of people beyond the scope of management in the Primary Dental Care setting eg day-stay and in-patient GA facilities, and conscious sedation for both severely anxious people and for those who are classified as ASA III or over on medical grounds

- Comprehensive care and joint planning with other Dental Specialists.

$\rightarrow$ The high volume of referrals has led to the development of strict patient acceptance criteria and where possible patients are accepted for a single course of, or one-off treatments only

$\rightarrow$ Close links with the local and other regional CDS teams allows patients to be transferred seamlessly to another service for continuing care

$\rightarrow$ Where patients are referred back to GDPs following treatment an open door approach for future patient care, or advice on such, is encouraged.

Fig. 2 Models of good practice outlined by JACSCD 1 likely to be less than 20 (informed best estimate)

- BSDH has 750 members, 500 of whom are dentists and most of whom overlap with other categories in this list

- Numbers of people in other related specialties comprise 266 in restorative dentistry, 220 in paediatric dentistry, and 343 in the prosthodontic monospecialty.

Clearly, only some of the above people will have the necessary skills and expertise to achieve mediated entry to SCD at specialist level, whilst others may demonstrate expertise at the DwSI level and thus contribute to a wider clinical network.

\section{Skills mix and facilities}

Whereas consultants and a large proportion of specialists have until recently had a strong hospital focus, there is recognition that not all of them need to be based in hospitals or, if they are, they may only provide certain aspects of care in a hospital setting. ${ }^{64,75}$ SCD should be predominantly community based. This would have the effect of reducing inequality in two ways:

1. Directly - by improving physical access to a specialist service that is not solely hospital based

2.Indirectly - by improving access through support for interested generalists in primary dental care.

Hospital services should be closely aligned with specialists in a community setting so that people who require hospital-based treatment because of medical complications, multidisciplinary care, and/or care under general anaesthesia, may do so seamlessly.

Ideally, the dental team will include dental care professionals (DCPs) such as dental therapists and dental hygienists, ${ }^{76}$ and may involve liaison with health promotion services to ensure that a preventive approach is taken locally to support health care for people with disability. ${ }^{34,54,71,72}$ Such an approach allows a proactive move to reduce and prevent dental disease rather than the currently common reactive approach of treatment of disease.

\section{Models of good practice}

The ideal interface between primary and specialist care should be seamless, 


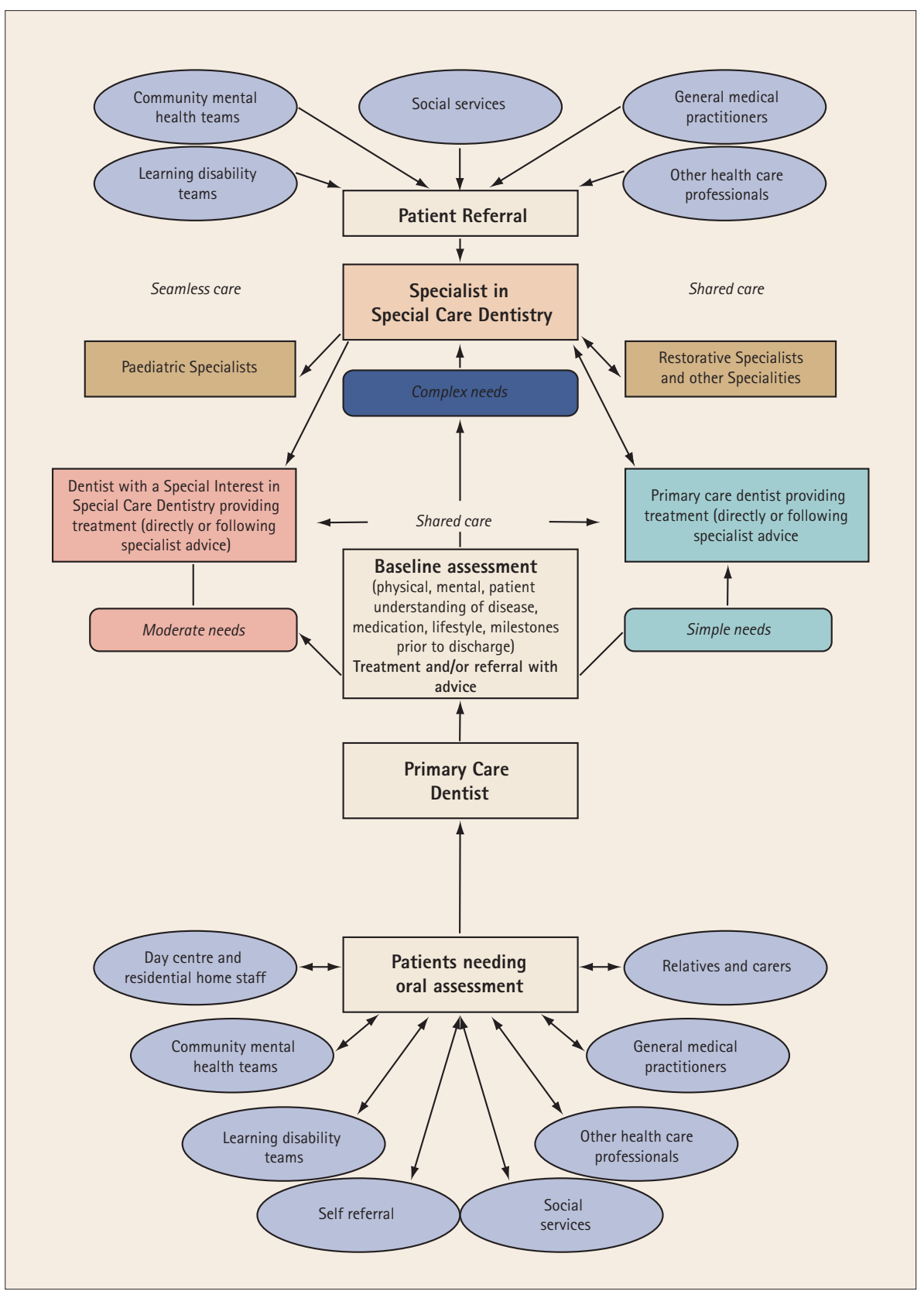

Fig. 3 Integrated model of Best Practice (Source: amended from JACSCD')

equitable, efficient and effective $e^{75,77,78}$ as demonstrated in Figure 3. Locally there needs to be an agreed strategy between primary care, DwSIs and specialists. Furthermore, seamless care with paediatric dentistry will be important to pick up teenagers as they move into adulthood. There may be agreed criteria for referral and discharge, and to promote clinical care pathways. Some Community Dental Services already have staff that have training in the field of SCD, and who have a keen interest and identified roles for providing a special care service. Some general dental practitioners have an interest in continuing care for long standing patients of their practices and discuss cases with in their own home or a community setting, with only the most vulnerable people living in care homes. It is recognised that there may be problems with transport and access to dental care. ${ }^{79}$ Practical local arrangements are required to improve access to care and to improve mechanisms of referral across organisations. Similarly, up-to-date information on dental services, such as domiciliary care, needs to be shared across organisations and agencies.

\section{The role of the generalist in the spectrum} of need

Generalists have the potential to play a major role in the provision of SCD. This role can, and would, be maximised if there was appropriate support for ongoing training and a robust specialist-led support service in place. Some primary dental care practitioners may have neither the experience nor the desire to provide care for people with disabilities. ${ }^{69}$ The provision of care for people with disability is often more complex and time consuming than for people without disability and some practitioners may be unwilling or unable to provide routine care because of the skills, facilities or remuneration available to them. A further quality issue is the volume of care that clinicians need to undertake in order to remain competent. Currently, with complex surgical cases, there is increasing acceptance that patients with certain conditions should be treated by a limited number of designated clinicians who have a high caseload and frequently used skills, rather than by practitioners who see only a low volume of cases. ${ }^{80-82}$ Additionally, for those people with certain impairments (such as learning disabilities and mental illness) the issues of informed consent, and appropriate physical intervention, present an extra challenge. ${ }^{72}$

essential that such care is of high quality and that it is co-ordinated with other agencies. ${ }^{30,33}$

\section{Improving access to dental care}

A range of initiatives should be explored to improve access to dental care in a proactive manner. For older people this may include linking into the single assessment process, with a defined oral health screening instrument and referral pathway to care at local level. This could be extended to all adults with a disability. The majority of older people and people with learning disability live

\section{Dentists with a Special Interest in SCD}

Some community and salaried dentists will have experience of treating patients with disability, but will not necessarily have the level of expertise in the necessary competencies to achieve mediated entry to a specialist list. This expertise should be harnessed in the new primary care system and recognised as a tier of people who can support both general dental practitioners and specialists by treating people with moderate disability. ${ }^{10,11}$ The number of dentists needed to 
provide SCD for a particular area may be a balance between specialists and DwSIs and depends on the professionals, with relevant competencies, available locally. What is important is that DwSIs and specialists work together in a clinical network (Fig. 3).

\section{Undergraduate education}

The requirement for SCD in the undergraduate curriculum is limited both in the $\mathrm{UK}^{83}$ and in other countries. ${ }^{1}$ This has resulted in a dental profession that, on the whole, feels poorly prepared to provide dental care services for people with disability and one that, in the main, finds it difficult to do so. ${ }^{84,85} \mathrm{BSDH}$ is reviewing current undergraduate training in SCD and making recommendations for curriculum development. ${ }^{86}$ The future specialist will need to contribute to the teaching and training of undergraduates, postgraduates and the wider dental team, including DCPs. In the long term, this will enable more care to be mainstreamed, in line with the strategy and policy recommendations for people with disability. ${ }^{30,33,75}$ It will be important for dental policy and local commissioning to support the use of these skills at local level.

\section{Liaison with other dental specialties and beyond}

As with any other section of the population, there will be times when it is appropriate to liaise with other specialties, such as Oral and Maxillofacial Surgery and Restorative Dentistry. When particular specialist competencies are required to address the oral health needs of people with disability there should be no hesitation in doing so. ${ }^{1}$

\section{Moving from 'here' to 'there'}

People with disability and additional complex needs currently receive care in a non-uniform manner and generally from socially committed and enthusiastic members of the profession, many of whom have received some training in an informal or piecemeal manner from various sections of the dental profession, often through role models and mentors. The diverse client group of people requiring SCD would benefit from improved access to routine dental care from general practitioners with a grounding in SCD. Where their needs and demands are beyond the scope of a generalist, they would also benefit from the services of designated DwSIs and the services of specialists. This is one of the greatest current challenges to the dental profession, but it is a silent challenge as many of these people do not have a public voice and are unable to express their needs and wishes.

A positive way forward involves the following:

- Teaching in SCD embedded in the undergraduate curriculum

- Access to oral healthcare within the primary dental care sector for people with disability who are able, and who wish, to access it

- The development of formal postgraduate training pathways in SCD

- Recognition of SCD as a specialty by the profession and the NHS

- Creation of managed clinical networks of special care dentists and clearly defined pathways of care

- Establishment of competency frameworks and training programmes for DwSIs in SCD.

\section{Promoting primary dental care}

All people with disability should have access to NHS primary dental care. The silent voice of this population may mean that this needs to be provided proactively. Routine primary dental care with local dentists, with the support and back up of specialists where required, is an appropriate option for the majority of people with mild and moderate special care requirements. Individual practitioners may wish to reflect on their current list of patients and whether it includes people with disability, and, if not, why this is the case. The interests of most people at the complex end of the spectrum of disability would be best served by specialists in SCD. Service planning must recognise that some patients will require lifelong care from DwSIs and/ or specialists due to: the complexity of their medical, dental and social needs; the resultant requirement for liaison with other health and voluntary sector professionals; difficulties in obtaining consent; and the multifaceted requirements for sedation or general anaesthesia services.

\section{Recognition of the specialty of Special Care Dentistry}

For such a specialty to be recognised within the NHS there needs to be action in accordance with the GDC's recommendation for the development of a specialty in SCD. The number of dentists who have experience and an interest in SCD, and who are likely to gain entry to a specialist list through the process of mediation can, at best, only be estimated - as in this paper.

Appointment of managed clinical networks of specialists and DwSIs

Whilst the estimated need for specialists is outlined in Figure 1, the recognition of specialists within the NHS should relate to local need. One hundred specialists would result in 2.5-3 whole time equivalents per total population level of 1.5 million. All new SHAs will have to determine the level of need for their population size, taking into account the age-profile and levels of reported disability locally.

Specialists may be supported by a wider team including Specialist Registrars on recognised training pathways, DwSIs, Staff Grade Dentists and DCPs, as well as providing education and support for other members of the SCD team.

Formal recognition of specialists and DwSIs will enable the creation of a managed clinical network and facilitate referrals to the network from across health, social services and the voluntary sector (Fig. 3). There need to be clear pathways of care for patients to ensure that people gain access to care at the appropriate level, thus ensuring that the skills and expertise of the profession are maximised. This will need to be monitored by local health organisations to ensure that it matches, as far as possible, the needs of the population.

\section{Higher specialist training programmes} and numbers

The development of a specialist list has been proposed and awaits the work of the GDC Specialist Dental Education Board to take it forward. JACSCD has already proposed a training programme for SCD. ${ }^{87}$ To progress, dentists with appropriate experience and skills in SCD need to be mediated onto the specialist list to provide a body of specialists who can act as trainers, and approved training programmes need to be in place to ensure that the workforce maintains an appropriate volume of specialist coverage across the UK. This assumes that there are 100 whole time specialists and 
that a specialist works for 20 years. If five specialists retire each year then five new trainees per year will be required to maintain the workforce. With a threeyear training programme, there would need to be 15 trainees at any one time.

Training specialists in SCD requires additional funded National Training Numbers to be allocated. If these are not forthcoming, legislation may throw the spotlight on the current NHS provision of care for people with a disability and the need for action to meet the legislative requirements of the Disability Discrimination Act.

\section{And finally...}

This paper has sought to provide a timely contribution to the current debate on the professional roles of primary dental care, specialist services and DwSIs in serving the needs of some of the most vulnerable groups within society. At such a time of immense change, it is only natural that the profession should be considering how best its own needs can be met. However, within the dental profession we have a responsibility to ensure that the needs of the most vulnerable sections of society are addressed and that access to health and health services with good health outcomes is equitable across societal groups. The question remains, can we formalise the care that has traditionally been provided by a relatively small number of socially committed dentists? Unless the profession rises to this challenge, the services that exist to date, and which have gained their skills through a variety of informal networks, are under threat and may well be lost.

Dr Janice Fiske MBE is the Chair of the Joint Advisory Committee for Special Care Dentistry and Dr Jenny Gallagher is a former representative on that Committee. Both these authors worked on the JACSCD document A case for need: proposal for a Specialty in Special Care Dentistry on which this paper is based. ${ }^{1}$

The authors wish to acknowledge the contribution of the other members of JACSCD to A case for need: proposal for a Specialty in Special Care Dentistry and thank them for their permission to use and reproduce information from that document. Finally the authors wish to thank Julie Gallagher for assistance in preparing this paper.

The views presented within this paper are the personal views of the authors, rather than the NHS organisations which they represent, or the Department of Health.

1. Joint Advisory Committee for Special Care Dentistry (JACSCD). A case for need: proposal for a Specialty in Special Care Dentistry. London: JACSCD, 2003.
2. Department of Health. Options for change. London: Department of Health, 2002.

3. Secretary of State, Health. Reforms with bite: 1,000 more dentists by October 2005: ministerial statement. London: UK Parliament, 2004.

4. United Kingdom Parliament. Health and Social Care Act. London: The Stationery Office, 2003.

5. Department of Health. NHS Primary Dental Care Services: implementation of local commissioning. Gateway Reference 5641. London: Department of Health, 2005

6. Chief Dental Officer. NHS dentistry: delivering change. London: Department of Health, 2004

7. Standing Advisory Committee. A review of the dentally based specialities and specialists lists. Report to the Chief Dental Officer for England of an expert group. London: Department of Health, 2004.

8. General Dental Council. Specialist Lists Review Group: final report. Item 14B 7 December 2005. London: General Dental Council, 2005.

9. Fiske J. Special care dentistry. Br Dent J 2006; 2: 61.

10. Department of Health \& Faculty of General Dental Practice. Implementing a scheme for dentists with a special interest (DwSI). London: Department of Health \& Faculty of GDP (UK), 2004.

11. Primary Care Contracting. Step by step guide to setting up a dentists with special interest (DwSI) service. London: NHS, 2006.

12. Gallagher J. Chapter 6. Specialties in transition. In Davies C (Ed). The future health workforce: Nuffield Trust \& University of Cambridge. pp 104-123. London: Palgrave Macmillan, 2003.

13. Department of Health. Creating the future: modernising careers for salaried dentists in primary care. London: Department of Health, 2004.

14. Department of Health. Creating the future: modernising careers for salaried dentists in primary care: stakeholder consultation response report. London: NHS Partners, HR Solutions in Health and Social Care, 2006.

15. Department of Health. Health Services Management: future development of community denta services. Health Circular HC(89)2. London: Department of Health, 1989.

16. Department of Health. Primary dental care: health service guidance. HSG(97)4. London: Department of Health, 1997.

17. National Working Group for Older People. Meeting the challenges of oral health for older people: A strategic review. Gerodontology 2005; 22 (Suppl).

18. Disability Partnership. One in four of us: the experience of disability. London: Disability Partnership (incorporating the Prince of Wales' Advisory Group on Disability), 2000.

19. Office of National Statistics. Census, 2001. www. statistics.gov.uk (Accessed 03.10.03)

20. Bennet N, Jarvis L, Rowlands 0 et al. Living in Britain: results from the 1994 General Household Survey. London: HMSO, 1996.

21. General Register Office for Scotland (2005). http://www.gro-scotland.gov.uk.

22. General Register Office for Northern Ireland (2005). http://www.groni.gov.uk/

23. Kerr M, Richards D, Glover G. Primary care for people with a learning disability - a group practice survey. J Applied Research in Intellectual Disability 1996: 9: 347-352.

24. Fiske J, Shafik H H. Down Syndrome and oral care. Dental Update 2001; 28: 148-156.

25. Cooper S. High prevalence of dementia among people with learning disabilities not attributable to Down's Syndrome. Psychol Med 1997; 27: 609-616.

26. Disability Partnership. Special or different: meeting and treating the health needs of people with learning disabilities. London: Disability Partnership (incorporating the Prince of Wales' Advisory Group on Disability), 2000.

27. Tinker A. Older people in modern society. $5^{\text {th }}$ edn London: Longman, 2002.

28. Tinker A. Ageing in the United Kingdom - what does this mean for dentistry? Br Dent J 2003; 194: 369-372.

29. Freeman $\mathrm{R}$, Adams $\mathrm{E}$, Gelbier $\mathrm{S}$. The provision of primary dental care for patients with special need. Primary Dental Care 1997; 4: 31-34.

30. Department of Health. Valuing people: a new strategy for learning disabilities for the $21^{\text {st }}$ century. London: Department of Health 2001. Cmnd 5086.

31. British Dental Association. Dental care for homeless people: a policy discussion paper. London: British Dental Association, 2003.

32. Kelly M, Steele J, Nuttall N et al. Adult dental health survey: oral health in the UK 1998. London: The Stationery Office, 2000.

33. Department of Health. National Service Framework for Older People. London: Department of Health, 2001.

34. British Society for Disability and Oral Health, Faculty of Dental Surgery and Diana Memorial Fund. Clinical guidelines and integrated care pathways for the oral health care of people with learning disabilities. London: Faculty of Dental Surgery, Royal College of Surgeons, England, 2000.

35. Fiske J, Gelbier S, Watson R M. Barriers to dental care in an elderly population resident in an inner city area. J Dent 1990; 18: 236-242.

36. Davis D M, Fiske J, Scott B, Radford D. The emotional effects of tooth loss: a preliminary quantitative study. Br Dent J 2000; 188: 503-506.

37. Fiske J, Davis D M, Frances C et al. The emotional effects of tooth loss in edentulous people. Br Dent J 1998; 184: 90-93.

38. Hunter M L, Hunter B, Thompson S A et al. Special Care Dentistry: attitudes of Specialists in Restorative Dentistry practising in the United Kingdom towards the creation of a new specialty. J Disabil Oral Health $2004 ; 6$ : 19-24.

39. UK Parliament. General Dental Services Regulations. London: TSO, 2005, SI 2005 [3361]

40. Stevens A, Rafferty J. Health Care Needs Assessment: the epidemiologically based needs assessment reviews. Oxford: Radcliffe Medical Press, 1994.

41. Stevens A, Rafferty J. Health Care Needs Assessment: the epidemiologically based needs assessment reviews. Oxford: Radcliffe Medical Press, 1997.

42. Stevens A, Gillam S. Needs assessment: from theory to practice. Br Med J 1998; 316: 1448-1452.

43. Williams R, Wright J. Epidemiological issues in health needs assessment. Br Med J 1998; 316: 1379-1382.

44. Wright J, Williams $\mathrm{R}$, Wilkinson J. Development and importance of health needs assessment. BrMed J 1998; 316: 1310-1313.

45. Culyer A J. Need: the idea won't do - but we still need it. Soc Sci Med 1995; 40: 727-730.

46. Department of Health. Tackling health inequalities a programme for action. London: Department of Health, 2003.

47. Russell G M, Kinirons M J. A study of barriers to dental care in a sample of patients with cerebra palsy. Comm Dent Health; 10: 57-64.

48. Fiske J, Boyle C. Epilepsy and oral care. Dental Update 2002; 29: 180-187.

49. Baird W O. Dental attendance pattern of people with multiple sclerosis. Master of Science in Health Services Research Dissertation; Leicester: University of Leicester, 2003.

50. Sjogren R, Nordstrom G. Oral health status of psychiatric patients. J Clinical Nursing 2000: 9: 632-638

51. Francis J R, Stevenson D R, Palmer J D. Dental health and dental care requirements of young handicapped adults in Wessex. Comm Dent Health 1997; 8: 131-137.

52. British Dental Association. Oral healthcare for older people: 2020 vision. London: British Dental Association, 2003

53. Tiller S, Wilson K I, Gallagher J E. The dental health and dental service use of adults with learning disabilities. Comm Dent Health 2001; 18: 167-171.

54. British Society for Disability and Oral Health. Guidelines for oral health care for people with mental health problems: Report of BSDH Working Party. London: BSDH, 2000.

55. Steele J G, Sheiham A, Marcenes W et al. National 
diet and nutrition survey; adults aged 65 and over. London: HMSO, 1998.

56. Lawton L. Providing dental care for special patients - tips for the general dentists. JADA 2002; 133: 1666-1670.

57. Friedlander A H, Marder S R. The psychopathology, medical management and dental implications of schizophrenia. JADA 2002; 133: 603-610.

58. Royal College of Paediatrics and Child Health. Health services for adolescents. London: RCPCH, 2002

59. Waldman H B, Perlman S P. Children with both mental retardation and mental illnesses live in our communities and need dental care. J Dent Child 2001; 66: 360-366.

60. Fiske J. Health services for adolescents - draft document: response to Royal College of Paediatrics and Child Health (Unpublished), 2002.

61. Nunn J. Professor in Special Care Dentistry: Personal communication, 2003.

62. Brookes V. Welcome Address. British Society for Disability and Oral Health Winter Meeting, London, 2004 www.bsdh.org.uk/scientific, 2004.

63. Pratelli P, Gelbier S. Perceived availability and use of dental service by adults with a learning disability living in private households within Lambeth Southwark and Lewisham; Department of Oral Health Services Research and Dental Public Health, King's College London (unpublished), 2000.

64. Mouatt B. The Chief Dental Officer's Report on UK specialist dental training. London: Department of Health, 1995.

65. Kaye P. Views and experiences of parents of adults with Down Syndrome: a qualitative and quantitative study. Master of Science Project in Sedation and Special Care Dentistry; GKT Dental Institute, University of London, 2001.
66. National Institute for Clinical Excellence. Dental recall: recall interval between routine dental examinations. London. NICE, 2004, Clinical guideline 19.

67. Dental Practice Board. DPB Registrations: GDS Quarterly Registration, 30 September 2003.

68. Service Users Advisory Group. Valuing People: A new strategy for learning disabilities for the $21^{\text {st }}$ Century: Good Health, 2003. www.doh.gov. uk/learning disabilities/access/section_7.htm (Accessed 21/09/2003).

69. Baird W O, McGrother C, Abrams K R et al. The views of the general dental practitioner on providing care to people with a physical disability. Submitted for publication.

70. Greater London Authority, London Health Observatory and London Health Commission. Health in London: review of the London health strategy high level indicators. London: London Health Commission, 2003.

71. British Society for Disability and Oral Health. Guidelines for oral health care for long-stay patients and residents: Report of BSDH Working Party. London: BSDH, 2000

72. British Society for Disability and Oral Health. Principles of intervention for people unable to comply with routine dental care. London: BSDH www.bsdh.org.uk/guidelines, 2004.

73. Kiyak H A. Impact of patients' and dentists' attitudes on older persons' use of dental services. Gerodontics 1988; 4: 331-335.

74. British Association of Oral and Maxillofacial Surgeons. The organisation of oral and maxillofacial surgical services in the UK. London: Council of The British Association of Oral and Maxillofacial Surgeons, 2002

75. HM Government \&t Department of Health. Our health, our care, our say. London: Department of Health, 2006, Cm 6367.

76. Goodwin M, Hanlon L, Perlman S P. Dental Hygiene Curriculum Study on Care of Developmentally Disabled. Boston: Forsyth Dental Centre, 1994.

77. Morris A J, Burke F J T. Primary and secondary dental care: the nature of the interface. Br Dent J 2001; 191: 660-665

78. Morris A J, Burke F J T. Primary and secondary dental care: how ideal is the interface. BrDent $\lrcorner$ 2001; 191: 666-671.

79. Health Select Committee. Access to NHS dentistry: first report. London: UK Parliament, 2001.

80. Clinical Standards Advisory Group. Clinical Standards Advisory Group: cleft lip and/or palate. London: The Stationery Office, 1998.

81. National Institute for Clinical Excellence. Improving outcomes in head and neck cancer: guidance on cancer services. London: Department of Health, 2004

82. The Specialist Training Authority of the Medical Royal Colleges. Specialist training, 2002. www.sta-mrc.org.uk.

83. General Dental Council. The first five years. $2^{\text {nd }}$ edn. London: General Dental Council, 2002.

84. Fiske J, Savidge G F, Smith M P et al. The treatment needs of adults with bleeding disorders. J Disabil Oral Health 2002; 3: 59-61.

85. Bedi R, Pollard D, Horn R. Attitudes of dental personnel towards people with Learning Disabilities. J Dent Res 1995; 74: 563-563.

86. Nunn J, Boyle C, Thompson S et al. Developing an undergraduate curriculum in Special Care Dentistry. J Disabil Oral Health 2005; 6: 3-15.

87. Joint Advisory Committee for Special Care Dentistry [JACSCD]. Training in Special Care Dentistry. London: JACSCD, 2003. 